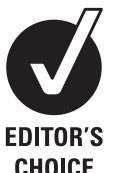

CHOICE

\title{
Using geographical information systems to assess the equitable distribution of traffic-calming measures: translational research
}

\author{
Sarah E Rodgers, ${ }^{1}$ Sarah J Jones, ${ }^{2}$ Steven M Macey, ${ }^{1}$ Ronan A Lyons ${ }^{1}$
}

${ }^{1}$ Centre for Health Information, Research and Evaluation, School of Medicine, Swansea University, Swansea, UK ${ }^{2}$ National Public Health Service for Wales and Department of Primary Care and Public Health, Cardiff University, Cardiff, UK

\section{Correspondence to}

Professor Ronan A Lyons,

Swansea University, School of

Medicine, Grove Building,

Singleton Park, Swansea SA2

8PP, UK; r.a.lyons@swansea. ac.uk

Accepted 24 September 2009

\section{ABSTRACT}

Objective To assess whether traffic-calming features are equitably distributed in the UK.

Design Cross-sectional database utilising geographical information system (GIS) and population data.

Setting Four large regions in England and Wales, including areas in south Wales, south-west England, east Midlands and Surrey, for which map data were available.

Main outcome measures The total proportion of road segments traffic calmed and the likelihood of road segments being traffic calmed by deprivation fifth.

Results A total of $3.7 \%$ of road segments was traffic calmed on $95791 \mathrm{~km}$ of road length. A higher proportion of traffic-calmed road segments was found in deprived areas when population density was taken into account. The odds of traffic calming in the most deprived areas, compared with the most affluent areas, was 2.83 (95\% Cl 2.815 to 2.835$)$.

Conclusions High resolution map data can be manipulated within a GIS to enable the distribution of traffic-calming measures to be assessed over large areas. There are very few traffic-calmed roads in any area and there is scope for more. Deprived areas have substantially more traffic calming. Making such data available to the public should be tested as an advocacy tool to increase the provision of traffic-calming features.

Globally, road traffic injuries kill approximately 1.3 million and injure 50 million people each year, and are the leading or second leading cause of death in children and young people aged 5-19 years. ${ }^{1}$ Children and older people tend to be at particular risk as pedestrians. ${ }^{2}$ Whereas the highest mortality rates occur in developing countries, the situation in many wealthy nations, although improving, is still a major public health issue. ${ }^{3}$ In the UK, child pedestrian mortality and injury rates remain a cause for concern, particularly compared with the low injury rates that exist for other road users. ${ }^{4}$ Based on 2006 data, the UK had the seventh lowest road death rate among 30 countries but was ranked 12 th lowest of 18 European countries in terms of child pedestrian deaths. ${ }^{5}$

Analysis of the factors underlying international variation in child road traffic mortality rates has suggested that countries with the lowest child casualty rates tend to have more speed-reduction measures, crossings controlled by signals and outside play areas. ${ }^{6}$ Traffic calming is an important speed-reduction measure. It forms a physical barrier to inappropriate speed, forcing drivers to change their behaviour. Logically, therefore, it should reduce injury risk. Most, but not all, studies of traffic calming have reported an impact on injury risk; however, few used high-quality research designs as part of their research. Child pedestrian injuries were found to decrease by $70 \%$ in 200 small areas that had been traffic calmed and injuries decreased $15 \%$ in Denmark following the installation of road engineering. $^{7-9}$ A meta-analysis by Elvik $^{10}$ found that, on average, area-wide traffic management, which included traffic calming, reduced injury collisions by $15 \%$, with larger reductions of up to $25 \%$ on residential streets. Mountain et al ${ }^{11}$ found that road engineering contributed to significant decreases in the number of total injuries $(40 \%$ decrease) and fatal and serious injuries (43\% decrease) in a study of UK speed management schemes, with the biggest effects being on child pedestrian injuries (62\% decrease, $95 \%$ CI $43 \%$ to $75 \%)$. In addition, an analysis of vertical deflectors only (speed humps), adjusted to estimate the effect caused only by traffic calming, found that these were associated with a $44 \%$ decrease in personal injury collisions and a $35 \%$ decrease in fatal and serious injuries. However, the use of traffic-calming measures can be controversial, with reports of problems for emergency services, public transport and complaints of excess noise. ${ }^{12-14}$

Child pedestrian injuries are strongly related to socioeconomic position, with significantly higher rates found in more deprived areas. Children living in the most deprived areas are three to eight times more likely to be injured as pedestrians than those living in more affluent areas. ${ }^{2} 3$ 15-17

Inequalities in injury are the product of complex social, economic and cultural factors. ${ }^{18}$ Researchers use exposure-based fatality rates for children in which average kilometres travelled on foot for each age group are used as the denominator. ${ }^{19}$ However, this does not take into account the variety of local environmental characteristics affecting pedestrian casualties that can be used to influence pedestrian facilities and traffic-calming measure locations. ${ }^{20}$ The application of complex models determining injury rates highlights the challenges within injury rate methodology, including determining pedestrian exposure to traffic. ${ }^{21}$ We do not propose to measure pedestrian exposure or model injury rates here Instead, we simply describe the pattern of trafficcalming features in relation to socioeconomic inequalities, one of many potential determinants of injury rates.

Given the high rate of overall pedestrian injuries and the scale of health inequalities in the UK it is important to look at causal factors in greater depth 
and to determine whether traffic calming is equitably distributed or follows the usual pattern of the inverse care law, whereby those at least risk in society are afforded the greatest protection. $^{22}$ In contrast to studies describing the distribution of injuries, there are few studies focussing on the distribution of protective interventions. A previous study of the distribution of traffic calming across two cities in the UK, following the introduction of the Traffic Calming Act in 1993, showed that one of the cities had traffic calming strongly concentrated in deprived areas. $^{2324}$ The distribution of traffic calming between the two cities seemed to be influenced by both the historical level of injurious motor vehicle collisions and influential local politicians. ${ }^{25}$ However, that study was limited to just two urban areas because it relied upon data collected manually during a systematic field survey, using hand-held global positioning system technology.

The development of geographical information systems (GIS), more powerful computers and high-resolution map data has made it possible to study the distribution of geographically distributed facilities across very large areas. This study aimed to describe the distribution of traffic calming across regions of England and Wales, using GIS, and to determine whether the distribution varies by deprivation across small areas.

\section{METHODS}

Digital road and traffic calming information in England and Wales is captured on the Ordnance Survey's MasterMap integrated transport network (ITN) layer. ${ }^{26}$ This is a digital dataset of the road network for Great Britain. Linked to the spatial data are tables containing information, including height restrictions, traffic calming and one-way roads. Traffic calming is defined as all speed humps (round or flat top), raised junctions and sections of road and speed cushions. The ITN layer also contains information on road segments across the UK, including 12-digit georeferences for junctions at the beginning and end of each segment.

The ITN files were obtained for substantial areas of England and Wales, including south Wales, south-west England, and parts of the east Midlands and Surrey, for analyses of traffic calming related to the Advocacy in Action cluster randomised trial. ${ }^{27}$ All road segments containing the label 'traffic calming' were identified within ArcMap ${ }^{28}$ for each small area. Analysis of traffic-calming distribution was carried out at the road segment level with the latest updates received in 2007.

Lower super output areas (LSOA) are the smallest geographical boundary areas developed for use in small area analysis in the UK and have an average population of $1500 .{ }^{29}$ LSOA are a consistent size and dimension and, unlike electoral divisions, are not subject to boundary changes. Electoral divisions are the geographical units used previously in these types of analyses. There is a total of 34378 LSOA in England and Wales (32 482 in
England, 1896 in Wales). Road segments were mapped to LSOA using the ITN files available to us, with 6647 LSOA within four separate areas being covered. All LSOA within the four areas were contiguous.

The total length of road was calculated for each LSOA along with the total length of traffic-calmed road segments. The percentage of total road length traffic calmed per LSOA was calculated. Population data from the 2001 census were obtained from the Office for National Statistics for each LSOA allowing population density to be calculated per LSOA. ${ }^{30}$ The Townsend index, derived from the 2001 census at LSOA level for England and Wales, was used as an area measure of deprivation. The Townsend deprivation index is widely used in health research, particularly in academic research and is considered to be valid and reliable. $^{31-33}$ LSOA were divided into five groups of equal numbers based on the Townsend index score, and will be referred to as deprivation fifths.

Summary statistics of the distribution of traffic calming by deprivation fifth were calculated. The likelihood of traffic calming per road segment was compared by deprivation fifth, adjusting for population density using weighted logistic regression in the statistical package R. ${ }^{34} 35$ Total road lengths were used to weight the traffic-calming lengths for each LSOA. Predicted probabilities were calculated and included as part of the results because these are often more easily understood than odds ratios. Represented as percentages, they are simply the sum of the likelihood of the event happening over the corresponding inverse; the likelihood of the event not happening (that is probability/1-probability)

\section{RESULTS}

This study analysed 124249 road segments in 6647 LSOA, which amounted to $95791 \mathrm{~km}$ of road, of which $3525 \mathrm{~km}$ comprised segments that were traffic calmed (3.7\%). Table 1 shows the summary descriptive analyses by deprivation fifth. The mean proportion of roads traffic calmed within each LSOA was $6.6 \%$, but across all LSOA the proportion of traffic-calmed road ranged from $0 \%$ to $98.1 \%$. The data demonstrated considerable positive skewness. Several transformations were attempted but the transformed data remained skewed. Variations by deprivation fifth were substantial. The most affluent fifth had both the lowest median traffic-calmed roads by LSOA (1.0\%) and the narrowest range of road calmed across all LSOA in the fifth category $(69.0 \%)$. In contrast, the most deprived fifth had a median proportion of roads traffic calmed by LSOA of $8.4 \%$ and a range of $95.1 \%$. Aggregating the data across all LSOA in a fifth showed a sixfold difference between the most affluent and deprived fifths $(2.4 \%, 12.2 \%)$.

Road segment lengths varied slightly between deprivation fifths, with median lengths of $59.1 \mathrm{~m}$ and $54.9 \mathrm{~m}$ in the most and least affluent fifths (Kruskal-Wallis test, $\chi^{2}=174.8,4 \mathrm{df}$,

Table 1 Summary statistics by deprivation fifth

\begin{tabular}{|c|c|c|c|c|c|c|c|c|c|}
\hline $\begin{array}{l}\text { Deprivation } \\
\text { fifths }\end{array}$ & $\begin{array}{l}\text { No of } \\
\text { LSOA }\end{array}$ & $\begin{array}{l}\text { Total road } \\
\text { length }(\mathbf{k m}) \\
\text { by LSOA }\end{array}$ & $\begin{array}{l}\text { Average road } \\
\text { length (km) } \\
\text { per LSOA }\end{array}$ & $\begin{array}{l}\text { Total traffic- } \\
\text { calmed road length } \\
(\mathrm{km}) \text { by LSOA }\end{array}$ & $\begin{array}{l}\text { Total traffic- } \\
\text { calmed \% } \\
\text { by LSOA }\end{array}$ & $\begin{array}{l}\text { Mean traffic- } \\
\text { calmed \% } \\
\text { by LSOA }\end{array}$ & $\begin{array}{l}\text { Median } \\
\text { traffic-calmed } \\
\% \text { by LSOA }\end{array}$ & $\begin{array}{l}\text { Range of LSOA } \\
\% \text { traffic calmed }\end{array}$ & $\begin{array}{l}\text { Total road } \\
\text { length (f) } \\
\text { by LSOA }\end{array}$ \\
\hline Most affluent & 1627 & 30161.70 & 18.54 & 714.80 & 2.4 & 4.0 & 1.0 & $69.0 \%(0-69.0 \%)$ & 18504.11 \\
\hline Next affluent & 1427 & 28402.81 & 19.90 & 606.58 & 2.1 & 4.4 & 1.0 & $88.7 \%(0-88.7 \%)$ & 19848.23 \\
\hline Median & 1463 & 17879.30 & 12.22 & 688.40 & 3.9 & 5.7 & 1.6 & $98.1 \%(0-98.1 \%)$ & 12146.27 \\
\hline Next deprived & 1362 & 13309.63 & 9.77 & 779.45 & 5.9 & 7.8 & 2.7 & $86.0 \%(0-86.0 \%)$ & 9672.70 \\
\hline Most deprived & 734 & 6037.02 & 8.22 & 735.82 & 12.2 & 15.9 & 8.4 & $95.1 \%(0-95.1 \%)$ & 8180.24 \\
\hline Total & 6647 & 95790.46 & 14.41 & 3525.05 & 3.7 & 6.6 & - & $98.1 \%(0-98.1 \%)$ & 14411.08 \\
\hline
\end{tabular}

LSOA, Lower super output area. 
Table 2 Logistic regression results; with each category of Townsend index compared with the most affluent fifth

\begin{tabular}{llll}
\hline Deprivation fifth & Estimate & $\mathbf{9 5 \%} \mathbf{C l}$ & p Value \\
\hline Most affluent fifth & Comparison & & \\
Next affluent fifth & 0.88 & 0.877 to 0.883 & $<0.001$ \\
Median fifth & 1.24 & 1.237 to 1.245 & $<0.001$ \\
Next deprived fifth & 1.56 & 1.555 to 1.565 & $<0.001$ \\
Most deprived fifth & 2.83 & 2.815 to 2.835 & $<0.001$ \\
Increase of 10 people per hectare & 1.22 & 1.224 to 1.225 & $<0.001$ \\
\hline
\end{tabular}

$\mathrm{p}<0.001)$. For all LSOA in this study, there was a mean population of 1507 people per LSOA, with a minimum of 1004 and a maximum of 4497 people per LSOA. The percentage of traffic calming per road segment was correlated with population density (Spearman's $r=0.23, p<0.001$ ) and population density increased with deprivation (Kruskal-Wallis test, $\chi^{2}=895.1,4 \mathrm{df}$, $\mathrm{p}<0.001)$.

Due to the highly skewed data and potential confounding by population density logistic regression was carried out to determine whether the presence of traffic calming in road segments was influenced by deprivation, adjusting for population density. Table 2 shows the results of the logistic regression analysis (Hosmer-Lemeshow goodness of fit test; $p=0.09$ ). Townsend fifth category and population density were both significant independent predictors of traffic calming. The odds of a trafficcalmed road segment was $12 \%$ lower in the next affluent compared with the most affluent. Traffic calming was most prevalent in the most deprived fifth, with 2.8 times the amount of traffic calming compared with that in the most affluent. In addition, for each increase of 10 people per hectare, the odds of traffic calming increased by a factor of 1.22 .

These findings can also be interpreted using predicted probabilities derived by holding the population per hectare constant at the mean (33.3 people per hectare). With population density held constant, the probability is that $2.91 \%$ of roads in the most affluent areas would be traffic calmed, compared with $7.63 \%$ of roads in the most deprived areas (figure 1 ).

\section{DISCUSSION}

The results of this study show that traffic-calming distribution heavily favours the most deprived areas. This is a positive finding because it indicates that there is a degree of social equity in traffic calming, given the overwhelming evidence of substantially higher pedestrian injuries among deprived groups..$^{2}{ }^{15-17}$ In recent years

\section{Percentage traffic calming for each deprivation fifth}

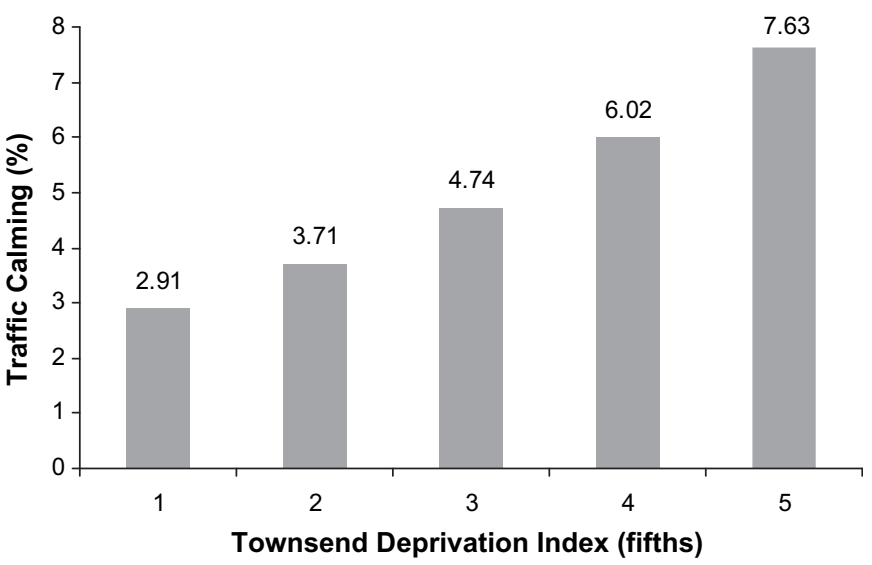

Figure 1 Percentage traffic calming for each deprivation fifth. there has been a narrowing of the inequality gap in child pedestrian injuries in the UK. ${ }^{36}$ It is not possible with this crosssectional research design to attribute a particular reduction of pedestrian injury inequality to the distribution of traffic calming. Other factors may also be involved, such as changes in modal transport, for example, reduced walking activity, and any other factor that reduces traffic speed. Nevertheless, given that empirical evidence suggests traffic calming is effective in curtailing the frequency and severity of road collisions, some reduction in injuries will have occurred in deprived areas. ${ }^{7-11}$ There are very few examples of health factors that run contrary to the inverse care law, and it is pleasing to see a population-based public health intervention that bucks the trend. ${ }^{22}$

It has been commented recently that the scope for making improvements in road safety using road engineering is reducing because they are believed to be at saturation, and that there should be a greater shift towards enforcement and education. ${ }^{36}$ However, our analyses suggest that there is still considerable potential for traffic-calming use in all areas; both affluent and deprived. The ranges of percentage traffic calming indicate that some LSOA are very heavily traffic calmed, but the overall figures of $3.7 \%$ and $12.2 \%$ in the most deprived areas, suggest that even in these areas, there is still relatively little traffic calming. Obviously, $100 \%$ coverage is impractical because speed humps are only suited to certain types of road, but the Audit Commission suggestion that there is little further scope for engineering is not supported by our findings. ${ }^{37}$

Although our study has several strengths it also suffers from a few limitations that must be considered when appraising the research findings. One major strength lies in the enormous amount of data collected in a standardised method over large parts of the UK. The study includes some 124249 road segments amounting to $95791 \mathrm{~km}$ of roads, distributed across 6647 LSOA (19.4\% of total in England and Wales). These large numbers ensure that the study had sufficient statistical power to detect important differences. The areas covered were chosen to be within $50 \mathrm{~km}$ of the five Advocacies in Action Study centres (Swansea, Cardiff, Bristol, Nottingham and Guildford) rather than representing any particular feature of road safety, and there is no obvious reason why the findings from this study should not be generalisable across England and Wales. ${ }^{27}$

One weakness of the study is that we were only able to obtain information on vertical traffic calming (speed bumps). Whereas Ordnance Survey's ITN data contain information on vertical traffic calming the equivalent horizontal features, such as chicanes and road narrowings, are not captured. In a previous study covering a smaller area, some of the authors of this investigation carried out a street-by-street audit allowing a broader view of traffic calming to be documented, including narrowings and chicanes as well as road humps. ${ }^{24}$ However, it is not logistically possible to carry out such audits on nearly $100000 \mathrm{~km}$ of road, as would have been the case had this methodology been adopted as part of this current study. Nevertheless, in the previous study, carried out in 2002, vertical calming was much more prevalent than horizontal calming. Given that we have not included horizontal calming measures, our results underestimate the full extent of traffic calming present in the areas studied. However, the size of any bias is probably small and there is unlikely to be significant variation in the method used by deprivation fifth (review of data from the study by Jones et a ${ }^{24}$ suggested that the proportions of vertical and horizontal deflectors were similar within each fifth). Our findings on the relative distribution of traffic calming by deprivation should thus be robust. Furthermore, it has been suggested 
that vertical deflectors are most effective at reducing speeds and pedestrian casualty rates. ${ }^{38}$ This study therefore provides a profile of the distribution of the single engineering approach with the greatest potential benefit for child pedestrian casualty prevention.

Another limitation of our method is that the MasterMap ITN layer data record whether there is any or no traffic calming on a road segment rather than displaying each specific feature. ${ }^{26}$ It is thus possible that a long segment of road may have just one speed hump on it, or three or four. Obviously, the impact on vehicle speeds and therefore collision risk is likely to be very different in these two scenarios. As a consequence, the extent of effective traffic calming within a traffic-calmed segment may be overestimated by our approach and be somewhat lower than the $3.7 \%$ of total length that we report here.

Although there is a considerable literature on social inequalities in pedestrian injuries, there is much less on the social distribution of countermeasures. ${ }^{23} 15-1724$ The mere existence of strategy and policy documents is insufficient to ensure that effective countermeasures are implemented. ${ }^{39}$ Neither the public nor policy makers have access to information on the distribution of countermeasures. Without such information it is difficult for groups to lobby effectively for further investment in prevention. We consider that there is a need to put such information into the public domain. Analyses such as those that form the basis of this research could be made available to the public. Information could be disseminated through government websites or that of the Injury Observatory for Britain and Ireland website. ${ }^{40}$ Whether such information leads to subsequent increased investment in preventive countermeasures and further reductions in injury inequalities are testable hypotheses.

\section{IMPLICATIONS FOR PREVENTION}

This research study indicates that it is possible to use highresolution map data within a GIS to measure and monitor the equitable distribution of traffic calming. Traffic calming in the UK is distributed in a manner that is likely to be reducing inequalities in child pedestrian injury rates, although the magnitude of this effect cannot be measured without further in-depth studies. There still appear to be very few traffic-calmed roads in most areas of England and Wales, whether deprived or affluent and thus, contrary to the suggestions of the Audit Commission, the scope for the introduction of additional road

\section{What is already known on this subject}

- Children living in the most deprived areas are more likely to be injured as pedestrians than those living in more affluent areas.

- Traffic calming is known to be an effective method of reducing speeds and pedestrian injury.

\section{What this study adds}

Traffic-calming features for large areas can be assessed using GIS and Ordnance Survey MasterMap data.

- Traffic-calming measures in the UK are distributed according to deprivation. The increased odds of traffic calming in the most deprived area compared with the most affluent area is 2.83 (95\% Cl 2.815 to 2.835 ). safety features across the UK continues to exist. Making local traffic-calming data publicly available, allowing it to be tested as an advocacy approach, represents an important recommendation for future research.

Acknowledgements Integrated Transportation Network data are all courtesy of Ordnance Survey. The authors would like to thank Dr Owen Bodger and Professor Michael Gravenor, both of Swansea University, for statistical advice.

Contributors RAL conceived the idea and contributed to the development of the methodology. SER carried out the GIS data preparation and statistical analyses. SJJ wrote the first draft of the manuscript and SER the subsequent drafts. SMM carried out the population analyses. All authors reviewed and critiqued the manuscript and made substantial intellectual contributions to subsequent drafts.

Competing interests None.

Provenance and peer review Not commissioned; externally peer reviewed.

\section{REFERENCES}

1. Peden M, Scurfield R, Sleet D, et al, eds. World report on road traffic injury prevention. Geneva: World Health Organization, 2004. http://whqlibdoc.who.int/ publications/2004/9241562609.pdf (accessed 26 Feb 2009).

2. Lyons RA, Jones SJ, Deacon T, et al. Socioeconomic variations in injury in children and older people: population based study. Inj Prev 2003;9:33-7.

3. UNICEF. A league table of child deaths by injury in rich nations. Innocenti report card no 2. Florence: UNICEF Innocenti Research Centre 2001. http://www.unicef-irc.org/ publications/pdf/repcard2e.pdf (accessed 26 Feb 2009).

4. Department for Transport. Road Casualties Great Britain 2007. London: Department for Transport, 2008. http://www.dft.gov.uk/pgr/statistics/datatablespublications/ accidents/casualtiesmr/rcgbmainresults2007 (accessed 26 Feb 2009).

5. Department for Transport. Road Casualties Great Britain 2006. London: Department for Transport, 2007. http://www.dft.gov.uk/pgr/statistics/datatablespublications/ accidents/casualtiesmr/rcgbmainresults2006 (accessed 26 Feb 2009).

6. Christie N, Towner E, Cairns S, et al. Children's road traffic survey: an international survey of policy and practice no 47. London: Department for Transport, 2004 http:// www.dft.gov.uk/pgr/roadsafety/research/rsrr/theme1/ (accessed 24 June 2009).

7. Towner $\mathbf{E}$, Dowswell $\mathrm{T}$, Mackereth $\mathrm{C}$, et al. What works in preventing unintentional injuries in children and young adolescents. London: Health Education Authority, 2001.

8. Webster DC, Mackie AM. Review of traffic calming schemes in $20 \mathrm{mph}$ zones. TRL Report 215. Crawthorne: TRL 1996.

9. Engel U. 'Short term' and area wide evaluation of safety measures implemented in a residential area named Osterbro. A case study. Seminar on short-term and areawide evaluation of safety measures. Amsterdam: Dutch Institute for Road Safety Research (SWOV) 1982

10. Elvik R. Area-wide urban traffic calming schemes: a meta analysis of safety effects Accid Anal Prev 2001;33:327-36.

11. Mountain LJ, Hirst WM, Mayher MJ, et al. Are speed enforcement cameras more effective than other speed management measures? The impact of speed management schemes on 30 mph roads. Accid Anal Prev 2005;37:742-54.

12. Garrod GD, Scarpa R, Willis KG, et al. Estimating the benefits of traffic calming on through routes: A choice experiment approach. J Transport Econ Policy 2002; 36:211-31.

13. Woolley JE, Klungboonkrong P, Taylor MAP. Some considerations of network traffic noise and a decision support system. Urban Transport and the Environment forth $21 \mathrm{st}$ Century II 1996;87-96.

14. Herrstedt L. Traffic calming design - a speed management method - Danish experiences on environmentally adapted through roads. Accid Anal Prev 1992;24:3-16

15. Edwards $\mathbf{P}$, Green J, Lachowycz K. Serious injuries in children: variation by area deprivation and settlement type. Arch Dis Child 2008;93:485-9.

16. Hewson P. Deprived children or deprived neighbourhoods? A public health approach to the investigation of links between deprivation and injury risk with specific reference to child road safety in Devon County, UK. BMC Public Health 2004;41:15.

17. Lascala EA, Gerber D, Gruenewald PJ. Demographic and environmental correlates of pedestrian injury collisions: a spatial analysis. Accid Anal Prev 2000;32: 651-8.

18. Christie N. “The high risk child pedestrian: socio-economic and environmental factors", Project Report 117, Transport Research Laboratory, Crowthorne, Berks: Transport Research Laboratory, 1995.

19. Christie N, Cairns S, Towner E, et al. How exposure information can enhance our understanding of child traffic "death leagues". Inj Prev 2007;13:125-9.

20. Graham DJ, Glaister S. Spatial variation in road pedestrian casualties: the role of urban scale, density and land-use mix. Urban Stud 2003:v40 n8 p1591-607.

21. Alexandrescu R, O'Brien SJ, Lecky FE. A review of injury epidemiology in the UK and Europe: some methodological considerations in constructing rates2). BMC Public Health 2009:9:226.

22. Tudor Hart J. The inverse care law. Lancet 1971;i:405-12.

23. Department of Transport. Traffic Calming Act. 1993. London: HMSO, 1993

24. Jones SJ, Lyons RA, John A, et al. Traffic calming policy can reduce inequalities in child pedestrian injuries: database study. Inj Prev 2005;11:152-6. 
25. Lyons RA, Jones SJ, Newcombe RG, et al. The influence of local politicians on pedestrian safety. Inj Prev 2006;12:312-15.

26. Ordnance Survey. OS MasterMap Integrated Transportation Network Layer user guide and technical specification (2007). http://www.ordnancesurvey.co.uk/ oswebsite/products/osmastermap/layers/itn/ (accessed 26 Feb 2009).

27. Lyons RA, Towner E, Christie N, et al. The Advocacy in Action Study: a cluster randomized controlled trial to reduce pedestrian injuries in deprived communities. Inj Prev 2008;4:136.

28. ESRI. ArcMap 9.2 edition. San Diego: ESRI, 1999-2006.

29. ONS Census Geography. Office of National Statistics (2007).

30. ONS. Neighbourhood Statistics http://www.neighbourhood.statistics.gov.uk/ dissemination/ (accessed 4 Nov 2009).

31. Townsend P, Phillimore P, Beattie A. Health and deprivation: inequality and the north London: Croom Helm, 1988

32. Galobardes B, Lynch J, Davey Smith G. (2007) Measuring socioeconomic position in health research. British Medical Bulletin 2007;81-82:21-37.

33. Gordon D. Area based deprivation measures: a UK perspective. In: Kawachi I, Berkman LF, eds. Neighborhoods and health. New York: Oxford University Press, 2003:179-207.
34. R Development Core Team. $R$ : A language and environment for statistical computing. Vienna, Austria: R Development Core Team, 2008. http://www.R-project. org

35. Harrel FE. Regression Modelling Strategies: with applications to Linear Models, Logistic Regression and Survival Analysis. Springer Series in Statistics. NY: Springer, 2001:p586.

36. Welsh Assembly Government. Chief Medical officer for Wales Annual Report - 2006. 2007 http://wales.gov.uk/dphhp/publication/cmo/reports/ report2006/cmoreport2006?lang=en (accessed 30 Jan 2009).

37. Audit Commission. Changing Lanes. Edited by Local Authorities and NHS E: Audit Commission; 64 2007. http://www.audit-commission.gov.uk/ SiteCollectionDocuments/AuditCommissionReports/NationalStudies/ 20070226changinglanesreport.pdf

38. Mackie AM. Urban speed management. TRL Report 363. Transport Research Laboratory, Crowthorne (1998).

39. Christie N, Towner E, Cairns S, et al. Children's road traffic safety: an international survey of policy and practice. Road Safety Research Report No 47. London, UK Department for Transport, 2004.

40. Injury Observatory for Britain and Ireland (IOBI). 2009, www.injuryobservatory. net (accessed 30 Jan 2009). 